\title{
Usefulness of Anterior-Based Periosteal (Palva) Flap for Obliteration of Mastoid Cavity in Canal Wall Down Mastoidectomy
}

\author{
Se-Joon Oh, MD, $\mathrm{PhD}^{1}$, Sung-Won Choi, $\mathrm{MD}, \mathrm{PhD}^{1}$, Hyeon-Jeong Lee, $\mathrm{MD}, \mathrm{PhD}^{2}$, \\ Seokwhan Lee, $\mathrm{MD}^{1}$ and Soo-Keun Kong, $\mathrm{MD}, \mathrm{PhD}^{1}$ \\ ${ }^{1}$ Departments of Otorhinolaryngology-Head and Neck Surgery, \\ ${ }^{2}$ Anesthesiology, Pusan National University School of Medicine, Biomedical Research Institute, \\ Pusan National University Hospital, Busan, Korea
}

\begin{abstract}
- ABSTRACT -
Background and Objectives : This study aimed to investigate the usefulness of anterior based periosteal (Palva) flap for mastoid cavity obliteration in canal wall down mastoidectomy (CWDM) and review its efficacy in producing a dry, low-maintenance cavity. Materials and Methods : Retrospective study of a consecutive series of procedures from 2012 to 2015. 122 consecutive procedures for chronic otitis media or cholesteatoma with a minimum follow-up of 12 months (mean, 21 mo; range, 12-40 months). Results : 67 ears of chronic otitis media and 41 ears of cholesteatoma were enrolled to this study, and others were adhesive otitis media (14 ears). 103 ears (84.4\%) maintained a small, dry, healthy mastoid cavity. 12 ears $(9.8 \%)$ had intermittent otorrhea easily controlled by topical treatment, 3 ears $(2.5 \%)$ had persistent otorrhea. 4 ears $(3.3 \%)$ had showed reperforation of tympanic membrane. Outcomes remained stable over long follow-up, up to 40 months. Conclusions : Obliteration of mastoid cavity following CWDM by an anterior-based periosteal flap is a reliable and effective technique that results in a dry, troublefree mastoid cavity in $84.4 \%$ of patients with active chronic otitis media. (J Clinical Otolaryngol 2019;30:199-203)
\end{abstract}

KEY WORDS : Canal wall down · Chronic otitis media - Obliteration · Periosteal flap · Tympanomastoidectomy.

\section{Introduction}

The primary goal in the surgical management of chronic otitis media (COM) is the creation of a dry, safe ear through the removal of disease and alteration of anatomy to prevent a recurrence. ${ }^{1)}$ Canal wall down mastoidectomy (CWDM) has several advantages such as excellent exposure and easy access to the mesotympanum and epitympanum, which allows the eradication of disease and postoperative observation. Howev-

논문접수일 : 2019년 9월 27일

논문수정일 : 2019년 11월 19일

심사완료일 : 2019년 12월 6일

교신저자 : 공수근

부산대학교 의과대학 이비인후과학교실

전화 : (051) 240-7336·전송 : (051) 246-8668

E-mail:entkong@gmail.com er, the potential problems such as chronic draining ear, dizziness with water exposure and the need for regular care of the mastoid cavity often occur. ${ }^{2)}$

Several methods of reducing cavity volume have been described, including amputation of the mastoid tip, saucerization and mastoid obliteration. Among these methods, mastoid obliteration includes various materials such as pedicled local soft tissue flaps, autologous and synthetic fillers. Soft tissue flaps and autologous bone pate have been used successfully to obliterate the mastoid cavity in CWDM surgery for over two decades. ${ }^{3)}$ Obliteration of the mastoid cavity is additionally important procedures performed at the end of CWDM surgery to minimize the potential problems by decreasing the size of the mastoid cavity and providing ventilation and easy access for postoperative cleaning the mastoid cavity, respectively. ${ }^{4)} \mathrm{Di}$ - 
verse techniques have been introduced, but usually these procedures were performed as independent processes. ${ }^{5)}$ So, the external auditory canal sometimes has an unnatural connection to the mastoid cavity which may lead to a hidden area from examination or irregularity of the mastoid cavity. ${ }^{6}$ Soft tissue flaps include various flaps such as fascia graft, palva or inferior based flap, and although each flaps have its advantages, we have used the palva flap mainly because of its ease of use and simplicity of its design. In addition, the palva flap has sufficient blood flow from the broad pedicle and nerve supply from the post auricular neve branch of facial nerve, which does not cause postoperative flap atrophy. ${ }^{7)}$ In the present study, we investigated the usefulness of the anterior based periosteal (Palva) flap for the obliteration of mastoid cavity in CWDM.

\section{MATERIALS AND METHODS}

A retrospective chart review was made of all patients who underwent CWDM surgery at the Pusan National University Hospital of Busan, the Republic of Korea from January 2012 to December 2015 for chronic otitis media with or without cholesteatoma. All the operations were performed CWDM with a procedure of mastoid cavity obliteration that uses an anteriorly based periosteal (palva) flap. All surgeries were performed by the two surgeons (S.J.O. and S. K.K.). A database was designed to record data including age, sex, side of surgery, preoperative and postoperative air-bone gap measurements, postopera- tive status of the canal wall and tympanic membrane, and findings at ossicular reconstruction including the presence of residual disease. Occurrences of postoperative infection and cholesteatoma recurrence were also investigated. We analyzed the control of suppuration and creation of a dry mastoid cavity according to the Merchant's grading system for evaluation of the efficacy of this technique (Table 1). ${ }^{8}$

\section{Surgical technique}

This technique begins with standard positioning and the usual retroauricular incision made $8-10 \mathrm{~mm}$ posteriorly to the postauricular skin crease. The incision is carried through the skin and into the subcutaneous tissue. The superficial and deep temporalis muscle fascia was dissected, harvested and dried as much as possible for tympanoplasty and covering the mastoid cavity. The anteriorly based musculoperiosteal flap was made according to Palva's method (Fig. 1). ${ }^{9)}$ The tympanomeatal flap was elevated following canal skin incision on the posterior canal wall $3 \mathrm{~mm}$ lateral to the tympanic annulus from 7 o'clock to 2 o'clock (left ear), or from 10 o'clock to 5 o'clock (right ear) and the middle ear cavity was exposed. Complete eradication of the middle ear and mastoid disease was performed using the method of CWDM. The auricle is reflected anteriorly and the conchal cartilage with perichondrium was harvested and used as a material for the obliteration of the epitympanum and mastoid antrum. Next, the anteriorly based musculoperiosteal flap was positioned to obliterate the mastoid cavity, which locates behind the posterior ca-

Table 1. Grading system to assess control of infection after surgery

\begin{tabular}{cc}
\hline Grade & Description \\
\hline 0 & No episode of otorrhea, and no pus or granulation on otologic examination \\
1 & One episode of otorrhea of $<2$ wk duration in a 3-month period or no otorrhea but a subjective feeling of \\
wetness in the ear & More than one episode of otorrhea in a 3-mo period, or an episode of otorrhea lasting more than 2 wk, \\
& or otologic examination showing localized granulation tissue/pus that was promptly cured with antibiotic \\
drop, curettage, or silver nitrate cautery & Constant purulent otorrhea on a daily basis, or otologic examination showing extensive granulation tissue, \\
or need for a revision procedure to control infection
\end{tabular}




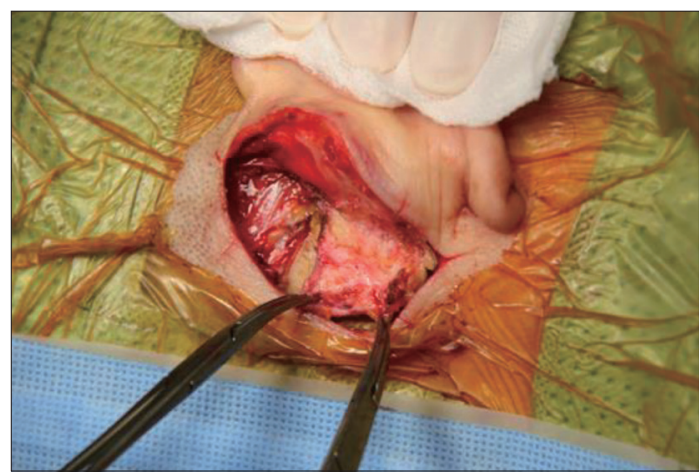

Fig. 1. The anteriorly based musculoperiosteal flap in right ear was made according to Palva's method.

nal skin. The mastoid cavity was packed with Gelfoam and the retroauricular incision was closed in a two-layer fashion with 3-0 vicryl and 5-0 nylon. The mastoid packing was removed 2 weeks postoperatively. The patient visited the clinic once every two weeks for 4 weeks postoperatively and then $2 \mathrm{nd}, 3 \mathrm{rd}$, 6th, 9th, 12th month.

\section{Results}

Table 2 presents the demographics at the time of CWDM surgery. CWDM was conducted in 122 ears. The most common cause for surgery was chronic otitis media (67 ears, $54.9 \%$ ), followed by cholesteatoma (41 ears, 33.6\%), adhesive otitis media (14 ears, $11.5 \%)$. CWDM was conducted on the right side in sixty six (54.1\%), and on the left side in fifty six (45.9\%) patients. Twenty patients (16.4\%) had a history of previous ear surgery. Mean postoperative follow-up time was 21 (range 6-40) months. Acute postoperative infection within 4 weeks was occurred in 3 patients, which were controlled by antibiotics. The ears that remained dry without recurrent disease was 103 ears (84.4\%). Twelve ears $(9.8 \%)$ had intermittent otorrhea while easily controlled by topical treatment, 3 ears $(2.5 \%)$ had persistent otorrhea. Four (4/122, 3.3\%) ears showed tympanic membrane reperforations. One $(1 / 122,0.8 \%)$ ear had evidence of residual keratin pearls (Fig. 2) (Table 2).
Table 2. Subject demographics and clinical data $(n=122)$

\begin{tabular}{lc}
\hline \multicolumn{1}{c}{ Characteristics } & Value \\
\hline $\begin{array}{l}\text { Age at implantation } \\
{[\text { year, mean, }(95 \% \mathrm{Cl})]}\end{array}$ & 50.0 \\
Gender, $\mathrm{n}(\%)$ & \\
Male & $69(56.6-62.3]$ \\
Female & $53(43.4)$ \\
Side of surgery, $\mathrm{n}(\%)$ & \\
Right & $66(54.1)$ \\
Left & $56(45.9)$ \\
Diagnosis, $\mathrm{n}(\%)$ & \\
Cholesteatoma & $41(33.6)$ \\
Adhesive otitis media & $14(11.5)$ \\
Chronic otitis media & $67(54.9)$ \\
Previous surgery & $20(16.4)$ \\
Results, $\mathrm{n}$ (\%) & \\
Dry, disease free cavity & $103(84.4)$ \\
Intermittent otorrhea & $12(9.8)$ \\
Persistent otorrhea & $3(2.5)$ \\
Reperforation of tympanic membrane & $4(3.3)$ \\
Recurrence of cholesteatoma & $1(0.8)$ \\
\hline &
\end{tabular}

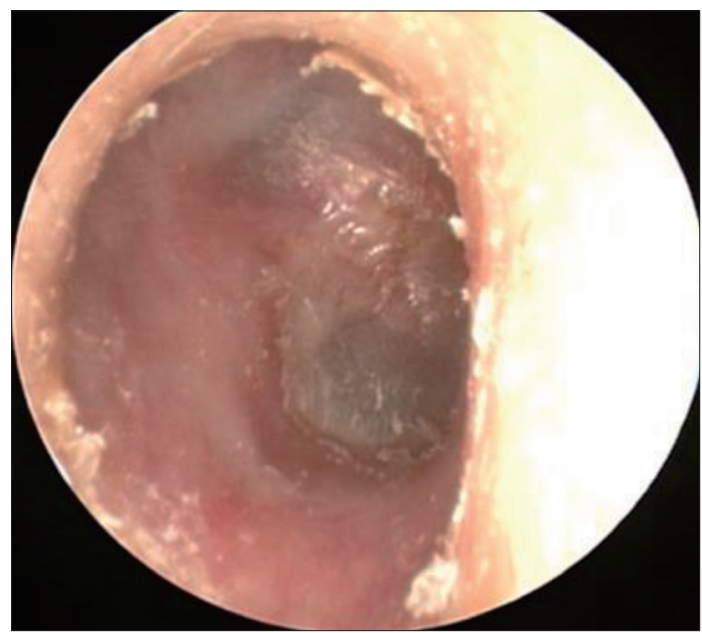

Fig. 2. Postoperative local finding of external auditory canal in right ear shows no inflammation signs and dry cavity.

\section{DISCUSSION}

While CWDM is a useful method among the management of COM with or without cholesteatoma, it is 
very important to make a safe, dry, trouble free ear in CWDM. $^{2)}$ To achieve this purpose, mastoid obliteration should be considered a routine part of CWDM designed to provide a well-epithelialized opening wide enough to properly ventilate the ear canal/mastoid cavity, yet allow for proper conduction of sound, an inspection of the cavity, and self-cleansing as a complete operation. ${ }^{10)}$ Although obliteration itself is important for avoiding cavity problems, how to obliterate the cavity is also as important. Various free grafts as a material for the obliteration of the mastoid cavity include bone pate, fat, cartilage, fascia and local muscle flaps, which minimize the potential problems by reducing the size of the mastoid cavity and promoting epithelialization over the exposed mastoid bone. ${ }^{11)}$ Since Mosher first described a local flap for mastoid obliteration, ${ }^{12)}$ a number of different flaps have been described, which include axial and random flaps, consisting of periosteum, temporoparietal fascia, temporalis fascia, and muscle. ${ }^{13)}$ The retro-auricular periosteal flap which described in the 1970s, consisted of retroauricular muscle and mastoid periosteum. However, the muscle atrophied over time, causing a progressive increase in cavity size. The flap was refined by maintaining the periosteum with excluding the muscular layer, resulting the allowance for improved contouring into the mastoid cavity, which not reduce its efficacy, rather the flap became more compliant. ${ }^{14)}$

The greatest advantage of this technique is its technical simplicity. In this technique, a Palva flap is placed into the mastoid cavity over the newly reconstructed cavity. The Palva flap, in turn, provides a suitable vascular bed to allow regrowth of skin from the Korner flap to the new reconstructed mastoid cavity. The early resolution of the wound is another advantage of this procedure. A Palva flap in the mastoid cavity prevents exposure of the obliterated material and necrosis of posterior canal wall (Korner flap) skin. ${ }^{15)}$

This study has a limitation, which cannot show any objective tool such as the measurement of mastoid cavity volume. However, the assessment for flap stability and infection could be investigated by local finding only.
In our study, this technique showed great results, with a high percentage $(84.4 \%)$ of ears maintaining a dry, safe and self-cleaning mastoid cavity. A few problems remained, which were resolved in the outpatient service. However, long-term follow-up will be needed in order to investigate the occurrence of residual cholesteatoma under the obliteration material or tympanic membrane retraction. One of the advantages of our technique is that this is a simple method that can be easily modifiable according to the shape or the volume of the mastoid cavity. The efficacy of our technique to make a dry and healthy mastoid cavity after CWDM is satisfactory, and the rate of complications was acceptably low. We expect this technique could be a feasible and useful method to prevent cavity problems in CWDM.

This work was supported by a 2-Year Research Grant of Pusan National University.

\section{REFERENCE}

1) Shohet JA, de Jong AL. The management of pediatric cholesteatoma. Otolaryngol Clin North Am 2002;35(4):841-51.

2) Bennett M, Warren F, Haynes D. Indications and technique in mastoidectomy. Otolaryngol Clin North Am 2006;39(6): 1095-113.

3) Ramsey MJ, Merchant SN, McKenna MJ. Postauricular periosteal-pericranial flap for mastoid obliteration and canal wall down tympanomastoidectomy. Otol Neurotol 2004; 25(6):873-8.

4) Cruz OL, Kasse CA, Leonhart FD. Efficacy of surgical treatment of chronic otitis media. Otolaryngol Head Neck Surg 2003;128(2):263-6.

5) Kos MI, Castrillon R, Montandon P, Guyot JP. Anatomic and fuctional long-term results of canal wall-down mastoidectomy. Ann Otol Rhinol Laryngol 2004;113(11):872-6.

6) Kim CW, Oh JI, Choi KY, Park SM, Park MI. A technique for concurrent procedure of mastoid obliteration and meatoplasty after canal wall down mastoidectomy. Auris Nasus Larynx 2012;39(6):557-61.

7) Vartiainen E, Härmä R. Mastoid obliteration in intact canal wall mastoidectomy. Clin Otolaryngol Allied Sci 1987;12 (5):327-9.

8) Merchant SN, Wang P, Jang CH, Glynn RJ, Rauch SD, McKenna MJ, et al. Efficacy of tympanomastoid surgery for control of infection in active chronic otitis media. Laryngoscope 1997;107(7):872-7.

9) Palva T, Makinen J. The meatally based musculoperiosteal flap in cavity obliteration. Arch Otolaryngol 1979;105(7): $377-80$. 
10) Portmann M. "How I do it"--otology and neurotology. A specific issue and its solution. Meatoplasty and conchoplasty in cases of open technique. Laryngoscope 1983;93 (4):520-2.

11) Mehta RP, Harris JP. Mastoid obliteration. Otolaryngol Clin North Am 2006;39(6):1129-42.

12) Mosher HP. A method of filling the excavated mastoid with a flap from the back of the auricle. Laryngoscope 1911;21: 1158-63.
13) Black B. Mastoidectomy elimination. Laryngoscope 1995; 105 (12 Pt 2 Suppl 76):1-30.

14) Merchant SN1, Schuknecht HF, Rauch SD, McKenna MJ, Adams JC, Wudarsky R, et al. The National Temporal Bone, Hearing, and Balance Pathology Resource Registry. Arch Otolaryngol Head Neck Surg 1993;119(8):846-53

15) Lasisi OA, Lawal HA. Deep temporalis fascia in tympanomastoid reconstruction. Afr J Med Med Sci 2007;36(2): 183-87. 